\title{
Supravalvular aortic stenosis-infantile hypercalcaemia syndrome: in vitro hypersensitivity to vitamin $\mathrm{D}_{2}$ and calcium
}

\author{
D. M. O. BECROFT* and DIANA CHAMBERS \\ From the Princess Mary Hospital for Children and the Department of Pathology, University of Auckland School \\ of Medicine, Auckland, New Zealand
}

\begin{abstract}
Summary. The incidence of cytoplasmic metachromasia has been studied in cultures of skin fibroblasts derived from 6 cases of the syndrome of supravalvular aortic stenosis, characteristic facies, and mental retardation which in many instances represents the late normocalcaemic stage of the severe form of infantile hypercalcaemia. The percentage of metachromatic cells (mean positivity $7.3 \%$ ) was significantly higher than in control cultures. The addition of vitamin $D_{2}$ and calcium to culture media caused a highly significant increase in metachromatic cells (mean positivity in supplemented media $16.1 \%$ ) compared with a lesser increase in controls. These findings strengthen previous suggestions that there is a geneticallydetermined hypersensitivity to vitamin $\mathrm{D}$ in some cases of the syndrome. A multifactorial aetiology is proposed, dependent on a variable genetic susceptibility of fetal connective tissues to a non-physiological effect of $D$ vitamins and a variable level of maternal vitamin $\mathrm{D}$ nutrition.
\end{abstract}

The syndrome in which supravalvular aortic stenosis is associated with mental retardation and a characteristic facies was described by Williams, Barratt-Boyes, and Lowe (1961). This association was confirmed by others (Black and Bonham Carter, 1963; Hooft, Vermassen, and Blancquaert, 1963; Beuren et al, 1964) who noted also that the 'elfin' facies in the syndrome resembled that of children with the severe form of idiopathic infantile hypercalcaemia (Schlesinger, Butler, and Black, 1956). The subsequent demonstration of supravalvular aortic stenosis in proven cases of severe idiopathic infantile hypercalcaemia has led to wide acceptance of the view that many, if not all, cases of the syndrome represent the late normocalcaemic stage of the latter disease (Garcia et al, 1964; Committee on Nutrition, American Academy of Pediatrics, 1967; Rowe and Cooke, 1969). Hypervitaminosis $\mathrm{D}$ has been considered a likely though unproven cause of idiopathic hypercalcaemia of

Received 16 May, 1975.

* Correspondence and reprint requests to Dr David M. O. Becroft, The Princess Mary Hospital for Children, Park Road, Auckland 3, New Zealand. infancy. Epidemiological studies have related an excessive postnatal dietary intake of vitamin $D$ to the occurrence of the mild form of the disease, but are not applicable to many cases of the severe form which clearly have their inception in utero (Fraser et al, 1966; Committee on Nutrition, American Academy of Pediatrics, 1967). However, more direct evidence for a role for vitamin $D$ in the aetiology of the severe form has come from the demonstration of high levels of vitamin D activity in the serum of some cases (Fellers and Schwartz, 1958; Fraser et al, 1966) and from the induction of similar aortic and facio-dental anomalies in animal fetuses by maternal hypervitaminosis $\mathrm{D}_{2}$ (Friedman and Roberts, 1966; Friedman and Mills, 1969). Excessive maternal exposure to vitamin $D$ has been considered unlikely in some cases and in these a special sensitivity of either mother or fetus to vitamin $D$ or vitamin $D$ metabolites has been suggested (Antia et al, 1967; Committee on Nutrition, American Academy of Pediatrics, 1967). The vascular and facio-dental anomalies would then be a manifestation of this hypersensitivity affecting developing mesenchymal tissues either directly or indirectly. 
TABLE

METACHROMASIA OF SKIN FIBROBLASTS IN BASIC MEDIUM

\begin{tabular}{|c|c|c|c|c|c|c|c|c|}
\hline \multirow{2}{*}{ Source of Fibroblasts } & \multirow{2}{*}{ Birth Date } & \multirow{2}{*}{ Sex } & \multirow{2}{*}{$\begin{array}{l}\text { Subcultures } \\
\text { Studied }\end{array}$} & \multicolumn{2}{|c|}{ Passages Before Study } & \multicolumn{3}{|c|}{$\%$ Metachromatic Cells } \\
\hline & & & & Range & Mean & Range & Mean & Median \\
\hline $\begin{array}{l}\text { Supravalvular aortic stenosis } \\
\text { Case } 1 \\
2 \\
3 \\
4 \\
5 \\
6\end{array}$ & 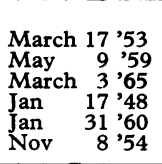 & $\begin{array}{l}F \\
\mathbf{M} \\
\mathbf{F} \\
\mathbf{F} \\
\mathbf{M} \\
\mathbf{M}\end{array}$ & $\begin{array}{r}11 \\
3 \\
9 \\
10 \\
1 \\
2\end{array}$ & $\begin{array}{r}10-30 \\
5-10 \\
14-37 \\
5-17 \\
7 \\
4-7\end{array}$ & & $\begin{array}{l}3-34.5 \\
0.5-2.5 \\
1.0-18.5 \\
0-13.2 \\
8.5-14.5\end{array}$ & $\begin{array}{r}9.1 \\
1.7 \\
5.8 \\
4.2 \\
6.5 \\
11.5\end{array}$ & $\begin{array}{r}9.0 \\
2.0 \\
4.5 \\
3.5 \\
6.5 \\
11.5\end{array}$ \\
\hline $\begin{array}{l}\text { All cases } \\
\text { All cases-first } 20 \text { passages }\end{array}$ & & & $\begin{array}{l}36 \\
25\end{array}$ & $\begin{array}{l}4-37 \\
4-20\end{array}$ & $\begin{array}{l}16.7 \\
10.1\end{array}$ & $\begin{array}{r}0-34.5 \\
0.5-16.5\end{array}$ & $\begin{array}{l}7.3 \\
5.3\end{array}$ & $\begin{array}{l}4.7 \\
4.5\end{array}$ \\
\hline $\begin{array}{l}\text { Normal controls } \\
\text { Strict* }-7 \text { cell lines } \\
\text { Cumulative* }-35 \text { cell lines }\end{array}$ & & & $\begin{array}{r}23 \\
127\end{array}$ & $\begin{array}{l}4-20 \\
1-30\end{array}$ & $\begin{array}{l}9.6 \\
8.2\end{array}$ & $\begin{array}{l}0-11 \\
0-23\end{array}$ & $\begin{array}{l}2.1 \\
1.3\end{array}$ & $\begin{array}{l}0.5 \\
0\end{array}$ \\
\hline
\end{tabular}

* See text.

In the course of a study of cultured skin fibroblasts in several congenital vascular diseases, an apparently excessive metachromasia was noted in fibroblasts from two cases of the supravalvular aortic stenosis-infantile hypercalcaemia syndrome. Doubling the concentration of calcium in the media did not alter this metachromasia. This report is of experiments designed to confirm the occurrence of abnormal metachromasia in a larger controlled series of cultures and of a preliminary investigation of the possibility of using metachromasia as a marker to show direct hypersensitivity of fibroblasts to vitamin $\mathrm{D}$ added to the medium. The design of the latter experiments allowed for the possibility that any effect of vitamin $\mathrm{D}$ in vivo might be conditioned by hyperoestrogenaemia prenatally or hypercalcaemia postnatally.

\section{Patients and methods}

Cases. Biopsies of forearm skin were obtained from 6 patients with the syndrome (see Table). Cases 1 and 4 (identified as $\mathrm{PW}$ and $\mathrm{HB}$ ) were included in the original report by Williams et al (1961). All had typical facies and mental retardation of varying severity. Supravalvular aortic stenosis had been shown by angiography in all and was confirmed at operation in 2 cases. Case 3 was known to have had hypercalcaemia in infancy and Case 2 had symptoms consistent with this. Control specimens of skin were obtained at minor surgical prodedures on otherwise normal children.

Culture methods. Fibroblast cultures were established and maintained in $90 \mathrm{ml}$ glass prescription bottles in an atmosphere of $10 \% \mathrm{CO}_{2}$ in air. Media changes were made twice weekly. Subculturing was performed after trypsinization when a monolayer had been achieved. The basic medium used was Eagles minimal essential medium (Burroughs Wellcome) supplemented with $10 \%$ fetal calf serum (Commonwealth Serum Laboratories) and gentamicin sulphate
$50 \mu \mathrm{g} / \mathrm{ml}$. All media were adjusted to $p \mathrm{H}$ 7.2. Experimental media were supplemented with combinations of the following: Calcium-1 $\mathrm{ml} 10 \%$ sterile aqueous calcium gluconate per $100 \mathrm{ml}$ of medium. Calcium was estimated by atomic absorption spectrophotometry and levels in the basic medium used for different experiments ranged from $0.7-1 \mathrm{mmol} / 1 \quad(2.8-4.3 \mathrm{mEq} / 1)$, and in the supplemented media from $1.9-2.4 \mathrm{mmol} / \mathrm{l}$ (7.6$9.6 \mathrm{mEq} / 1$ ). Vitamin $D-1 \mathrm{ml}$ of vitamin $D_{2}$, in arachis oil (British Drug Houses) was emulsified in $9 \mathrm{ml}$ fetal calf serum by sonication and $0.1 \mathrm{ml}$ emulsion added per $100 \mathrm{ml}$ medium to give a final concentration of 30 International Units $/ \mathrm{ml}$. Oestrogen-10 $\mathrm{mg}$ of $17 \beta$ oestradiol (Ikapharm) was dissolved in $1 \mathrm{ml}$ of $1-2$ propylene glycol and dispersed in $9 \mathrm{ml}$ fetal calf serum. After filtration sterilization $1 \mathrm{ml}$ filtrate was added per $100 \mathrm{ml}$ basic medium. The content of $17 \beta$-oestradiol was estimated fluorometrically after extraction in ether, and levels of between 0.68 to $1.84 \mu \mathrm{g} / \mathrm{ml}$ were obtained in the media used for different experiments. Two combinations of supplements were used; (a) calcium and vitamin $\mathrm{D}$ and (b) calcium, vitamin $\mathrm{D}$, and oestrogen.

Demonstration of cytoplasmic metachromasia. The effects of the supplements were examined in a series of experiments in which various combinations of cultures from one or more cases of the syndrome, one or more controls and, on occasion, from cases of mucoviscidosis or Hurler's syndrome were studied in parallel. A bottle of actively growing cells near confluence from each was subcultured, each into 6 culture bottles each containing 2 coverslips. Cultures were maintained in basic medium for 2 to 3 days until active growth was observed. Each set of 6 bottles was then divided into 1 pair for continued culture in basic medium and 2 pairs for culture in each of the two experimental media. Culture was continued for a further 10 days to 2 weeks depending on the time for confluence to be reached in most cultures. Coverslips were then removed, rinsed in normal saline, fixed in absolute methanol for 5 minutes, stained with $0.5 \%$ toluidine blue (Harleco) in $60 \%$ methanol for 5 minutes followed by changes in acetone, acetone/xylol 
and xylol before mounting. Cultures from a case of Hurler's syndrome and sections of human umbilical cord provided positive controls for the staining procedures.

Slides were coded and 1000 cells were examined from each of the paired culture bottles and the mean percentage showing distinct red or pink cytoplasmic staining recorded. Coverslips were surveyed in a pattern designed to give a uniform representation of the margins of the coverslip, where in some instances, more cells were metachromatic.

${ }^{35} \mathrm{~S}$ uptake. In some experiments carrier-free${ }^{35} \mathrm{SO}_{4}{ }^{-}$- (Radiochemical Centre) was added, $5 \mu \mathrm{Ci} / \mathrm{ml}$ of medium, over the final 3 days of culture. Coverslips were removed as above and the remaining cells were detached by trypsinization, washed, and counted numerically before filtration through a $3 \mu$ pore-size 'Millipore' filter. The filter was rinsed with $5 \%$ trichloracetic acid, dried at $80^{\circ} \mathrm{C}$ for one hour, and placed in $10 \mathrm{ml}$ 'Triton' toluene scintillant for counting in a Packard 'Tricarb' liquid scintillation counter.

Statistics. Statistical analyses were performed using either the Mann-Whitney $U$ test or, where applicable, Wilcoxon's matched pairs signed ranks test.

\section{Results}

Cultural characteristics. The growth rate of cell lines derived from patients with the syndrome was variable but the impression overall was of a reduced rate in comparison with the majority of control cultures. Otherwise there were no distinctive cultural features, and no differences in the growth patterns or in $p \mathrm{H}$ changes were seen between parallel cultures of the same cell lines grown in the basic and supplemented media.

Metachromasia in basic medium (Table and Figure). The incidence of cells showing cytoplasmic metachromasia varied from cubculture to subculture of the same cell line, but was consistent within paired bottles of the same subculture maintained under identical conditions. Most positively staining cells in cultures from cases of the syndrome had metachromatic granules or vesicles which were restricted to one part of the cytoplasm, few showing the diffuse intense cytoplasmic staining of cultured cells from the case of Hurler's syndrome. In repetitive studies these metachromatic cells were readily detected in the majority of cultures from the 5 of the 6 cases of the syndrome whereas serial cultures from the majority of controls showed either no metachromasia or a low percentage of positive cells in isolated cultures only. The mean percentage of positive cells in 36 cultures from the 6 cases was $7.3 \%$, the

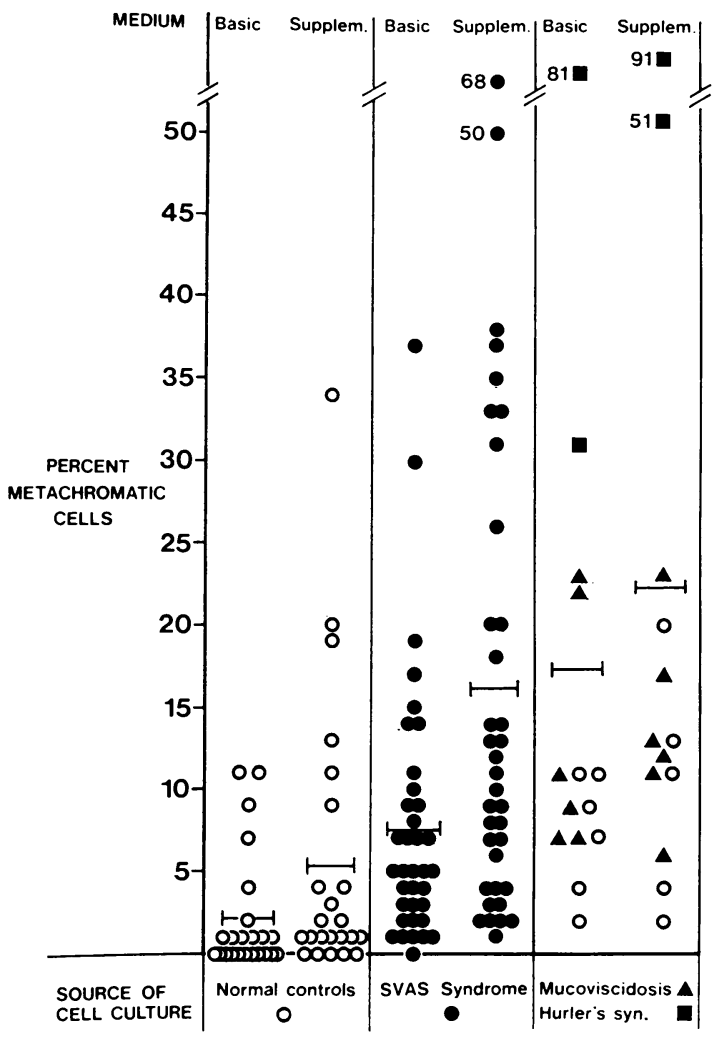

Fig. A comparison of the incidence of cytoplasmic metachromasia in paired cultures of fibroblasts maintained in either a basic medium or medium supplemented with vitamin $D_{2}$ and calcium. Results from normal controls at left; from cases of the supravalvular aortic stenosis-infantile hypercalcaemia syndrome (SVAS) at centre; and from cases of mucoviscidosis, Hurler's syndrome, and normal controls showing excessive initial metachromasia at right.

median was $4.7 \%$ and the incidence overall was significantly higher $(P<0.0001)$ than in the 23 cultures from 7 controls studied in strict parallel in which the mean positivity was $2.1 \%$ and the median $0.5 \%$. A further comparison with the incidence of positivity in 127 cultures from 38 controls which had been studied over a longer period of time showed differences with an even higher level of significance, but this larger cumulative series was also not strictly comparable in that the period of subculture before staining was less than 10 days in a minority of studies. A higher incidence of metachromatic cells was noted in ageing cultures from cases of the syndrome, but a comparison restricted to cultures within the first 20 passages still showed significant differences between cases and strict controls $(P<0.005)$. 
Metachromasia in supplemented media (Fig). The addition of vitamin $\mathrm{D}_{2}$ and calcium to the 36 cultures derived from cases of the syndrome caused an overall increase in metachromatic cells, the mean percentage rising from 7.3 to $16.1 \%$. The increase was significant $(P<0.005)$ and was immediately obvious on microscopical examination of many paired preparations. A greater proportion of cells showed diffuse cytoplasmic metachromasia. Control cultures also showed an overall increase in the incidence of metachromatic cells, the mean increasing from 2.1 to $5.3 \%$ but this change was rarely obvious on direct microscopical examination and was of lesser significance $(0.01<$ $P<0.025)$. In terms of the absolute increase in the percentage of positive cells the difference between the effect of supplementation on cultures from cases of the syndrome and from controls was highly significant $(P<0.005)$. However, in both series there was an approximate doubling of the initial mean incidence of metachromatic cells and therefore the possibility of a proportionate effect was examined further in seven cell lines showing excessive metachromasia in basic media (see Fig). These included cell lines from cases of Hurler's syndrome and mucoviscidosis. With supplementation the mean incidence of metachromatic cells increased from 17.3 to $22.6 \%$, a change which was much smaller proportionately and not significant.

The second experimental medium containing oestrogen, in addition to vitamin $\mathrm{D}_{2}$ and calcium, also caused a significant increase in metachromasia in cultures from cases of the syndrome but this increase was slightly less than that produced by vita$\min D_{2}$ and calcium alone. No difference was observed between the uptake of ${ }^{35} \mathrm{~S}$ per cell in those cultures derived from cases of the syndrome and control cultures, nor between the uptake of cells grown in basic medium and those in supplemented media.

\section{Discussion}

An abnormal accumulation of metachromatic material in the cytoplasm of cultured skin fibroblasts was reported first in the mucopolysaccharide storage diseases and in mucoviscidosis (Danes and Bearn, 1966, 1968), but subsequently the phenomenon has been identified in many diseases and in a minority of normal individuals (Matalon and Dorfman, 1969; Taysi et al, 1969; Danes, Scott, and Bearn, 1970). The large differences in the incidence and severity of metachromasia reported in various studies has been attributed in part to differing criteria and in part to the modifying effect of many variables in the conditions of culture (Milunsky and Littlefield, 1969; Kraus et al, 1971; Lie, McKusick, and Neufeld, 1972). In most instances the metachromatic material has been identified as sulphated mucopolysaccharide but other cell constituents may stain metachromatically (Matalon and Dorfman, 1969). The phenomenon is inconsistent and lacks specificity, but according to Bearn and Danes (1970), 'can provide a simple but useful indicator of a possible inherited trait which demands further investigation'.

We have identified a small but significant increase in metachromasia in cultures from cases of the supravalvular aortic stenosis-infantile hypercalcaemia syndrome compared with controls. The variability between cases, and between different subcultures from single cases, is similar to that which has been encountered in other diseases. No abnormal metachromasia was detected in all three cultures from one clinically typical patient and, by analogy with the interpretation placed on similar negative findings in a minority of typical cases of mucoviscidosis, this may indicate genetic heterogeneity.

Bajwa, Morrison, and Ershoff (1971) have described an accumulation of metachromatic material in the vascular lesions induced by hypervitaminosis $\mathrm{D}$ in the rat. Therefore, our further investigation of the implied genetically-determined trait in this syndrome was based on the premise that metachromasia itself might be used as a marker for abnormal connective tissue reactivity to vitamin $D$. Fibroblasts were cultured in media supplemented with vitamin $D_{2}$ and calcium to levels similar to those reported in the sera of some cases of the syndrome (Schlesinger et al, 1956; Fellers and Schwartz, 1958; Black and Bonham Carter, 1963; Garcia et al, 1964). The resulting increase in metachromasia was significantly greater than that in controls and this is interpreted as further evidence for the presence of a genetically-determined hypersensitivity to vitamin $D_{2}$ in the syndrome. This interpretation has to be qualified in respect to the possible synergistic effect of two factors associated with vitamin $D_{2}$ in the culture medium; first, increased calcium concentration which alone had no effect, and second, the suspending oil which was introduced at high dilution has no known biological activity and is not itself metachromatic. Further studies are required to exclude synergism and to investigate the effects of lesser concentrations of vitamin $\mathrm{D}_{2}$ and of other $\mathrm{D}$ vitamins and metabolites. Supplementation with $17 \quad \beta$-oestradiol was investigated because of the possibility that oestrogens might influence the response of con- 
nective tissues in utero (Priest, 1967), but no additive effect was observed.

The metachromatic material has not been identified as yet. No increase was detected in the rate of synthesis of sulphated mucopolysaccharides as measured by the cellular incorporation of ${ }^{35} \mathrm{~S}$, using a method in which cultures from a case of Hurler's syndrome had an average uptake four times that of controls. However, the cytological metachromasia was considerably less intense than in Hurler's syndrome and the method may have been insufficiently sensitive to detect a proportionately lesser accumulation of sulphated mucopolysaccharide.

The hyperreactivity of cultured fibroblasts to vitamin $\mathrm{D}$ is likely to be independent of the physiological functions of the vitamin. The conversion of vitamin $\mathrm{D}_{2}$ to the metabolites active in calcium metabolism in vivo normally occurs in liver and kidneys (De Luca, 1973) and would not be expected in fibroblast cultures. The vitamin D content of the media used in these experiments was considerably less than the very high levels which have been required to alter calcium metabolism in other in vitro systems (Trummel et al, 1969). Even the latter effect may have been non-physiological and analogous to the direct effects of pharmacological doses of vitamin $\mathrm{D}$ on bone and cartilage which Weisbrode, Capen, and Nagode (1973) have observed in thyroparathyroidectomized rats.

A hypothesis that the supravalvular aortic stenosis-infantile hypercalcaemia syndrome is the result in part of hyperreactivity of connective tissues to a non-physiological effect of vitamin D is consistent with the suggestion by Antia et al (1967) that the hypercalcaemia and the vascular lesions are separate phenomena of common cause. Thus, the anatomical features would be induced by either large or small increases in maternal intake, synthesis, or retention of vitamin $\mathrm{D}$, depending on the degree of inherited susceptibility of the fetus. The critical period for this induction is uncertain but the structure of the supravalvular aortic lesions (Gasul, Arcilla, and Lev, 1966) in which there is a constricting internal ring of connective tissue and often no external constriction, suggests that this is late in gestation. The later development of hypercalcaemia in infancy, though based on sensitivity to vitamin $\mathrm{D}$, could have different determinants including the physiological activities of the vitamin and less dependence on maternal levels. This hypothesis would also be consistent with the clinical variability, suggested multifactorial aetiology and occasional familial occurrence of the syndrome (Garcia et al., 1964).
Stamp and Round (1974) found that human plasma levels of 25-hydroxyvitamin D were highest in late summer and at the same time were signicantly higher in adult females than in males. They concluded that summer sunlight in Britain is a major determinant of vitamin $\mathrm{D}$ nutrition. A similar or greater effect of sunlight would be anticipated in New Zealand and, therefore, it is of interest that 5 of the 6 cases of the syndrome under study were born between January and early May (see Table) which, in the Southern Hemisphere, would have allowed substantial maternal exposure to sunlight during the third trimester of pregnancy. The seasonal occurrence of the syndrome is being investigated further.

We thank Dr J. B. Lowe, Physician-in-Charge, Cardiology Unit, Green Lane Hospital, for permission to study patients in his care; Dr Patricia Clarkson for reviewing case records and Dr John France, Postgraduate School of Obstetrics and Gynaecology, University of Auckland for the estimation of $17 \beta$ oestradiol. The work was supported by grants from the Auckland Medical Research Foundation and the Medical Research Council of New Zealand.

\section{REFERENCES}

Antia, A. U., Wiltse, H. E., Rowe, R. D., Pitt, E. L., Levin, S., Ottesen, O. E., and Cooke, R. E. (1967). Pathogenesis of the supravalvular aortic stenosis syndrome. Fournal of Pediatrics, 71, 431-441.

Bajwa, G. S., Morrison, L. M., and Ershoff, B. H. (1971). Induction of aortic and coronary athero-arteriosclerosis in rats fed a hypervitaminosis D, cholesterol-containing diet. Proceedings of the Society for Experimental Biology and Medicine, 138, 975-982. Bearn, A. G. and Danes, B. S. (1970). Metachromasia elaborated. New England fournal of Medicine, 282, 102.

Beuren, A. J., Schulze, C., Eberle, P., Harmjanz, D., and Apitz, J. (1964). The syndrome of supravalvular aortic stenosis, peripheral pulmonary stenosis, mental retardation and similar facial appearance. American fournal of Cardiology, 13, 471-483.

Black, J. A. and Bonham Carter, R. E. (1963). Association between aortic stenosis and facies of severe infantile hypercalcaemia. Lancet, 2, 745-749.

Committee on Nutrition, American Academy of Pediatrics (1967) The relation between infantile hypercalcemia and vitamin $D-$ public health implications in North America. Pediatrics, 40 1050-1061.

Danes, B. S. and Bearn, A. G. (1966). Hurler's syndrome. A genetic study in cell culture. Fournal of Experimental Medicine, $123,1-16$.

Danes, B. S. and Bearn, A. G. (1968). A genetic cell marker in cystic fibrosis of the pancreas. Lancet, 1, 1061-1063.

Danes, B. S., Scott, J. E., and Bearn, A. G. (1970). Further studies on metachromasia in cultured human fibroblasts. Fournal of Experimental Medicine, 132, 765-774.

DeLuca, H. F. (1973). The kidney as an endocrine organ for the production of 1,25-dihydroxyvitamin D3, a calcium-mobilizing hormone. New England fournal of Medicine, 289, 359-365.

Fellers, F. X. and Schwartz, R. (1958). Etiology of the severe form of idiopathic hypercalcemia of infancy. A defect in vitamin D metabolism. New England fournal of Medicine, 259, 1050-1058.

Fraser, D., Kidd, B. S. L., Kooh, S. W., and Paunier, L. (1966). A new look at infantile hypercalcemia. Pediatric Clinics of North America, 13, 503-525.

Friedman, W. F. and Mills, L. F. (1969). The relationship between vitamin $D$ and the craniofacial and dental anomalies of the supravalvular aortic stenosis syndrome. Pediatrics, 43, 12-18. 
Friedman, W. F. and Roberts, W. C. (1966). Vitamin D and the supravalvular aortic stenosis syndrome. The transplacental effects of vitamin D on the aorta of the rabbit. Circulation, 34, 77-86.

Garcia, R. E., Friedman, W. F., Kaback, M. M., and Rowe, R. D. (1964). Idiopathic hypercalcemia and supravalvular aortic stenosis. Documentation of a new syndrome. New England fournal of Medicine, 271, 117-120.

Gasul, B. M., Arcilla, R. A., and Lev, M. (1966). Heart Disease in Children, p. 819. J. B. Lippincott, Philadelphia and Montreal.

Hooft, C., Vermassen, A., and Blancquaert, A. (1963). Observations concerning the evolution of the chronic form of idiopathic hypercalcemia in children. Helvetia Paediatrica Acta, 18, 138-147.

Kraus, I., Antonowicz, I., Shah, H., Lazarus, H., and Schwachman, H. (1971). Metachromasia and assay for lysomal enzymes in skin fibroblasts cultured from patients with cystic fibrosis and controls. Pediatrics, 47, 1010-1018.

Lie, S. O., McKusick, V. A., and Neufeld, E. F. (1972). Simulation of genetic mucopylysaccharidoses in normal human fibroblasts by alteration of $\mathrm{pH}$ of the medium. Proceedings of the National Academy of Sciences of the United States of America, 69, 2361-2363.

Matalon, R. and Dorfman, A. (1969). Acid mucopolysaccharides in cultured human fibroblasts. Lancet, 2, 838-841.

Milunsky, A. and Littlefield, J. W. (1969). Diagnostic limitations of metachromasia. New England fournal of Medicine, 281, 11281129.
Priest, R. E. (1967). Endocrine control of connective tissue metabolism. In The Connective Tissue, p. 50. Ed. B. M. Wagner and D. E. Smith. Williams and Wilkins, Baltimore.

Rowe, R. D. and Cooke, R. E. (1969). Vitamin D and craniofacial and dental anomalies of supravalvular aortic stenosis. Pediatrics, 43, $1-3$.

Schlesinger, B. E., Butler, N. R., and Black, J. A. (1956). Severe type of infantile hypercalcemia. British Medical fournal, 1, 127134.

Stamp, T. C. B. and Round, J. M. (1974). Seasonal changes in human plasma levels of 25-hydroxyvitamin D. Nature (London), 247, 563-565.

Taysi, K., Kistenmacher, M. L., Punnett, H. H., and Mellman, W. J. (1969). Limitations of metachromasia as a diagnostic aid in pediatrics. New England fournal of Medicine, 281, 1108-1111. Trummel, C. L., Raisz, L. G., Blunt, J. W., and DeLuca, H. F. (1969). 25-Hydroxylcholecalciferol: stimulation of bone resorption in tissue culture. Science, 163, 1450-1451.

Weisbrode, S. E., Capen, C. C., and Nagode, L. A. (1973). Fine structural and enzymatic evaluation of bone in thyroparathyroidectomized rats receiving various level of vitamin D. Laboratory Investigation, 28, 29-37.

Williams, J. C. P., Barratt-Boyes, B. G., and Lowe, J. B. (1961). Supravalvular aortic stenosis. Circulation, 24, 1311-1318. 